\title{
Partial oxidation of toluene to benzaldehyde and benzoic acid over model vanadia/titania catalysts: role of vanadia species
}

\author{
Dmitri A. Bulushev, Fabio Rainone, Lioubov Kiwi-Minsker* \\ Swiss Federal Institute of Technology, LGRC-EPFL, CH-1015 Lausanne, Switzerland
}

Available online 3 August 2004

\begin{abstract}
Pure and K-doped vanadia/titania prepared by different methods have been studied in order to elucidate the role of vanadia species (monomeric, polymeric, bulk) in catalytic toluene partial oxidation. The ratio of different vanadia species was controlled by treating the catalysts in diluted $\mathrm{HNO}_{3}$, which removes bulk vanadia and polymeric vanadia species, but not the monomeric ones, as was shown by FTRaman spectroscopy and TPR in $\mathrm{H}_{2}$. Monolayer vanadia species (monomeric and polymeric) are responsible for the catalytic activity and selectivity to benzaldehyde and benzoic acid independently on the catalyst preparation method. Bulk $\mathrm{V}_{2} \mathrm{O}_{5}$ and $\mathrm{TiO}_{2}$ are considerably less active. Therefore, an increase of the vanadium concentration in the samples above the monolayer coverage results in a decrease of the specific rate in toluene oxidation due to the partial blockage of active monolayer species by bulk crystalline $\mathrm{V}_{2} \mathrm{O}_{5}$. Potassium diminishes the catalyst acidity resulting in a decrease of the total rate of toluene oxidation and suppression of deactivation. Deactivation due to coking is probably related to the Brønsted acid sites associated with the bridging oxygen in the polymeric species and bulk $\mathrm{V}_{2} \mathrm{O}_{5}$. Doping by $\mathrm{K}$ diminishes the amount of active monolayer vanadia leading to the formation of non-active K-doped monomeric vanadia species and $\mathrm{KVO}_{3}$.
\end{abstract}

(C) 2004 Elsevier B.V. All rights reserved.

Keywords: V/Ti-oxide catalysts; Toluene partial oxidation; K-doping; Surface vanadia species; Raman spectroscopy

\section{Introduction}

V/Ti-oxides are known to catalyse partial oxidation of hydrocarbons, selective reduction of $\mathrm{NO}_{x}$, ammoxidation of alkylaromatics and oxidative dehydrogenation of hydrocarbons. The state of vanadia in the catalysts is non-uniform. Under dehydrated conditions V/Ti-oxides contain isolated monomeric species, polymeric species, and bulk $\mathrm{V}_{2} \mathrm{O}_{5}$ [1-7].

Benzaldehyde (BA) and benzoic acid (BAc) are the most valuable products of toluene partial oxidation formed by consecutive pathway from toluene. It is a lot of evidence that the specific rate (per $\mathrm{m}^{2}$ of the catalyst) of toluene oxidation increases with vanadia coverage up to one monolayer, however, at higher coverage it was found to decrease [8], to be stable up to two monolayers $[9,10]$ and to increase up to high coverage [11]. The reasons of such discrepancy could be due to the presence of impurities in the titania support,

\footnotetext{
* Corresponding author. Tel.: +41 21693 3182; fax: +41 216936091 .

E-mail address: lioubov.kiwi-minsker@epfl.ch (L. Kiwi-Minsker).
}

mainly $\mathrm{K}$ and $\mathrm{P}[4,10]$, which are known to influence the structure of vanadia surface species $[4,6,12,13]$ affecting the activity, selectivity and stability towards coking.

The treatment of V/Ti-oxides in aqueous solutions of acids and bases results in partial removal of vanadia from the surface [2,4,14-17]. The removal of bulk $\mathrm{V}_{2} \mathrm{O}_{5}$ and polymeric species has been already reported $[2,18]$. The coverage by vanadia species after this treatment was found in the range of 0.1-0.4 monolayer (ML) [4], but the higher than 1 ML coverage was also reported [16].

The insoluble in acids and bases vanadia was shown to catalyse oxidative dehydrogenation reactions [4], isopropanol conversion to acetone and total $o$-xylene oxidation [2]. The activity of the catalysts containing only insoluble in $\mathrm{HNO}_{3}$ species in ammoxidation of methylpyrazine was found higher than before the $\mathrm{HNO}_{3}$ treatment [16]. In contrast, a decrease in activity after such treatment was reported for $o$-xylene oxidation [2]. The role of insoluble species was not studied in toluene partial oxidation.

Spectroscopic information on the structure of insoluble species is quite limited [4]. Octahedral vanadium coordination 
followed from the ${ }^{51} \mathrm{~V}$ NMR studies of the $\mathrm{HNO}_{3}$ treated V/Tioxide [16]. However, isolated monomeric species with tetracoordinated vanadium was found by Raman spectroscopy in the Eurocat V/Ti-oxide catalysts after treatment in $\mathrm{NH}_{4} \mathrm{OH}$ [17]. The contradiction [16,17] could be assigned to the conditions of measurement (hydrated/dehydrated [1]) and to the different vanadia concentration in the samples remained after treatment.

Recently, we reported a detailed characterisation of the model vanadia/titania catalysts treated in diluted $\mathrm{HNO}_{3}[18]$. The present work is aimed on the elucidation of the role of different vanadia species in partial toluene oxidation regarding catalytic activity, selectivity and stability. The catalytic activity of vanadia/titania was compared within the series of the samples prepared by solid-state reaction, by impregnation and grafting. Effect of K-doping was studied for the catalysts prepared by impregnation and containing the same vanadia loading in the form of monolayer vanadia species. Bulk $\mathrm{V}_{2} \mathrm{O}_{5}$ and $\mathrm{TiO}_{2}$ were also tested and characterised.

\section{Experimental}

\subsection{Catalyst preparation}

Detailed synthesis of the support and catalysts is reported elsewhere [18]. The characteristics of the mainly studied samples are presented in Table $1 . \mathrm{A} \mathrm{TiO}_{2}$ support was prepared by hydrolysis of the tetrapropylorthotitanate $(>98 \%$, Fluka). This titania was shown to possess an anatase structure and specific surface area (SSA) of $57 \mathrm{~m}^{2} \mathrm{~g}^{-1}$. Monolayer catalyst with 1.8 wt.\% of vanadium ( $0.37 \mathrm{ML}$ $\mathrm{V} / \mathrm{TiO}_{2}$ ) was prepared via a well-known grafting technique $[4,5]$ by three-steps of $\mathrm{VOCl}_{3}$ vapour deposition on the surface of the $\mathrm{TiO}_{2}$, followed by hydroxylation and drying. Impregnated catalyst containing $11.1 \mathrm{wt} . \%$ of vanadium (2.6 $\mathrm{ML} \mathrm{V/TiO}{ }_{2}$ ), was synthesised by a three-step wet impregnation with vanadium oxalate solution (prepared from $\mathrm{V}_{2} \mathrm{O}_{5}$
(>99.6\%, Aldrich, SSA-9.1 $\mathrm{m}^{2} \mathrm{~g}^{-1}$ ) and oxalic acid (>97\%, Fluka)). After calcination for $120 \mathrm{~min}$ at $723 \mathrm{~K}$ the SSA of these catalysts were equal to 57 and $50 \mathrm{~m}^{2} \mathrm{~g}^{-1}$, respectively. The amount of vanadium in the catalysts corresponds to 0.37 and $2.6 \mathrm{ML}$ coverage of titania by $\mathrm{VO}_{x}$ species $\left(1 \mathrm{ML}=10 \mathrm{~V}-\right.$ atom $\left(\mathrm{nm}^{-2}\right)$ [4]).

Two treatments of the catalysts for $25 \mathrm{~min}$ in excess of an aqueous solution of $\mathrm{HNO}_{3}(1.2 \mathrm{~N})$ were performed to remove some surface vanadia. After washing in deionised water, the catalysts were dried and calcined at $723 \mathrm{~K}$ for $30 \mathrm{~min}$ in air.

For the preparation of the samples by a solid-state reaction $[14,19]$ a titania (Alfa, $>99.9 \%$ ) containing $89 \%$ of anatase phase and $11 \%$ of rutile was used. The SSA was found equal to $49 \mathrm{~m}^{2} \mathrm{~g}^{-1}$. Intensively ball-milled $(1 \mathrm{~h})$ physical mixtures of $\mathrm{V}_{2} \mathrm{O}_{5}$ with $\mathrm{TiO}_{2}$ were calcined in air for $11 \mathrm{~h}$ at $723 \mathrm{~K}$ and then for $34 \mathrm{~h}$ at $773 \mathrm{~K}$ to obtain the

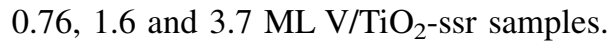

To study an effect of K-doping a series of V/Ti-oxide catalysts with a smaller vanadia coverage $(0.2 \mathrm{ML})$ was prepared via wet co-impregnation of home made titania by aqueous solution of vanadium oxalate with potassium oxalate obtained in the reaction of $\mathrm{K}_{2} \mathrm{CO}_{3}$ (puriss, Fluka) and oxalic acid. After drying, the samples were calcined for $120 \mathrm{~min}$ at $723 \mathrm{~K}$ in air. The vanadium concentration in the samples was equal to $1.2-1.4 \mathrm{wt} . \%\left(0.2 \mathrm{ML} \mathrm{V} / \mathrm{TiO}_{2}-\mathrm{K}_{x}\right.$ series) and SSA was in the range of $69-77 \mathrm{~m}^{2} \mathrm{~g}^{-1}$ corresponding to the vanadia coverage $0.19-0.24 \mathrm{ML}$.

\subsection{Experimental set-up and procedure}

The kinetic studies were performed in the experimental set-up described in [20]. The installation allowed a quick switch from one gas flow to another. The reactor was a quartz tube. The catalyst was diluted by quartz beads in a $1: 3$ weight ratio. Oxygen (99.95\%), argon (99.998\%) (Carbagas, Lausanne) and toluene $(>99.5 \%$, Fluka) were used as received without further purification. Toluene was intro-

Table 1

Characteristics of the studied vanadia/titania catalysts

\begin{tabular}{|c|c|c|c|c|c|c|}
\hline Catalyst & $\begin{array}{l}\mathrm{V}_{2} \mathrm{O}_{5} \text { content } \\
\text { (wt. } \% \text { ) }\end{array}$ & $\begin{array}{l}\text { SSA } \\
\left(\mathrm{m}^{2} \mathrm{~g}^{-1}\right)\end{array}$ & $\begin{array}{l}\mathrm{VO}_{x} \text { coverage } \\
(\mathrm{ML})^{\mathrm{a}}\end{array}$ & $\begin{array}{l}\text { Method of } \\
\text { preparation }\end{array}$ & $\begin{array}{l}\mathrm{K} / \mathrm{V} \text { atomic } \\
\text { ratio }\end{array}$ & $\begin{array}{l}\text { Steady-state } \\
\text { activity } \times 10^{-16} \text { at } 523 \mathrm{~K} \\
\text { (toluene molecule, } \mathrm{s}^{-1} \mathrm{~m}^{-2} \text { ) }\end{array}$ \\
\hline \multicolumn{7}{|c|}{ Catalysts on the base of the Alfa titania (SSA $=49 \mathrm{~m}^{2} \mathrm{~g}^{-1}$ ) } \\
\hline $0.76 \mathrm{ML} \mathrm{V} / \mathrm{TiO}_{2}$-ssr & 4.3 & 35 & 0.76 & Solid-state reaction & 0 & 0.12 \\
\hline $1.6 \mathrm{ML} \mathrm{V} / \mathrm{TiO}_{2}$-ssr & 8.0 & 32 & 1.6 & Solid-state reaction & 0 & 0.44 \\
\hline 3.7 ML V/TiO ${ }_{2}$-ssr & 14.8 & 27 & 3.7 & Solid-state reaction & 0 & 0.29 \\
\hline \multicolumn{7}{|c|}{ Catalysts on the base of the home made titania $\left(\mathrm{SSA}=57 \mathrm{~m}^{2} \mathrm{~g}^{-1}\right.$ ) } \\
\hline $0.37 \mathrm{ML} \mathrm{V} / \mathrm{TiO}_{2}$ & 3.2 & 57 & 0.37 & Grafting & 0 & 0.22 \\
\hline $2.6 \mathrm{ML} \mathrm{V} / \mathrm{TiO}_{2}$ & 19.8 & 50 & 2.6 & Impregnation & 0 & 0.067 \\
\hline \multicolumn{7}{|c|}{ Catalysts on the base of the home made titania ( $\mathrm{SSA}=84 \mathrm{~m}^{2} \mathrm{~g}^{-1}$ ) } \\
\hline $0.2 \mathrm{ML} \mathrm{V} / \mathrm{TiO}_{2}-\mathrm{K}_{0}$ & 2.1 & 76 & 0.19 & Impregnation & 0 & $0.70^{\mathrm{b}}$ \\
\hline $0.2 \mathrm{ML} \mathrm{V} / \mathrm{TiO}_{2}-\mathrm{K}_{0.25}$ & 2.1 & 77 & 0.22 & Impregnation & 0.25 & $0.56^{\mathrm{b}}$ \\
\hline $0.2 \mathrm{ML} \mathrm{V} / \mathrm{TiO}_{2}-\mathrm{K}_{1}$ & 2.5 & 69 & 0.24 & Impregnation & 1 & $0.07^{\mathrm{b}}$ \\
\hline
\end{tabular}

${ }^{\mathrm{a}}$ Monolayer is taken equal to $10 \mathrm{~V}$ atom $\mathrm{nm}^{-2}$.

${ }^{\mathrm{b}}$ Measured at $573 \mathrm{~K}$. 
duced into a heated evaporator by a syringe-pump. The catalyst loading corresponded to $4.0 \mathrm{~m}^{2}$ and flow rate was $60 \mathrm{~mL}$ (STP) $\mathrm{min}^{-1}$. Before the reaction, all the catalysts were pre-treated in oxidative atmosphere $\left(20 \mathrm{vol} . \% \mathrm{O}_{2}\right.$ in Ar) for $30 \mathrm{~min}$ at $673 \mathrm{~K}$. Then the temperature was decreased to 523 or $573 \mathrm{~K}$ and the flow was switched to the reaction mixture of 2 vol.\% toluene with 40 vol. $\% \mathrm{O}_{2}$ in Ar.

Gas composition was analysed with a Balzers QMG-421 mass-spectrometer and a Perkin-Elmer Autosystem XL gaschromatograph with two capillary columns for analysis of organic and inorganic $\left(\mathrm{CO}, \mathrm{CO}_{2}\right)$ products.

Toluene conversion was calculated from the detected BA, BAc, maleic anhydride (MA) and $\mathrm{CO}_{x}$. Other by-products were present in trace concentrations. Selectivity was calculated as the number of moles of toluene converted into the product divided by the total number of converted toluene moles. To compare the catalytic activity of the samples specific rates of the toluene oxidation referred to the total surface area were used. The conversions were below $10 \%$. The carbon balance was within $100 \pm 5 \%$.

\subsection{Catalyst characterisation}

Raman spectroscopic studies were performed with a Perkin-Elmer FT-Raman 2000 spectrometer. A Raman spectroscopy in situ cell [7] was attached to the same set-up as was applied for the kinetic experiments. A Nd:YAG laser, operating at $1064 \mathrm{~nm}$ with a power in the range of 10$750 \mathrm{~mW}$ was used in the Raman spectrometer. Sixty-four scans were taken with a resolution of $4 \mathrm{~cm}^{-1}$ and averaged to obtain a spectrum. The spectrum of a catalyst was measured in the flow of dry $20 \mathrm{vol} . \% \mathrm{O}_{2} / \mathrm{Ar}$ mixture $\left(60 \mathrm{ml}(\mathrm{STP}) \mathrm{min}^{-1}\right)$ at 363 or $523 \mathrm{~K}$ after pre-treatment at $673 \mathrm{~K}$ for $30 \mathrm{~min}$. These conditions of the pre-treatment and measurement correspond to the dehydrated ones [1].

Temperature programmed reduction (TPR) experiments were performed in a Micromeritics AutoChem 2910 analyser with a quartz plug-flow reactor. Hydrogen concentration was determined by a Thermostar 200 quadrupole massspectrometer (Pfeiffer Vacuum). The catalysts were pretreated in oxidative atmosphere $\left(2 \mathrm{vol} . \% \mathrm{O}_{2}\right.$, rest $\left.\mathrm{He}\right)$ at $673 \mathrm{~K}$ for $30 \mathrm{~min}$, and then cooled down to $323 \mathrm{~K}$. After purging with $\mathrm{Ar}$, the reactor was heated up in a mixture of 4 vol. $\%$ of $\mathrm{H}_{2}$ in $\mathrm{Ar}\left(20 \mathrm{ml}(\mathrm{STP}) \mathrm{min}^{-1}\right)$ with a constant heating rate $\left(20 \mathrm{~K} \mathrm{~min}^{-1}\right)$. The catalyst loading corresponded to $4 \mathrm{~m}^{2}$. A thermocouple was inserted into the middle of the catalytic bed.

Pyridine temperature-programmed desorption experiments were performed with the set-up used for the TPR studies connected to the mass-spectrometer. The surface area of the catalysts placed into the reactor corresponded to $2.2 \mathrm{~m}^{2}$. The catalysts were pre-treated in oxygen $\left(10 \mathrm{vol} . \% \mathrm{O}_{2} / \mathrm{He}\right)$ at $673 \mathrm{~K}$ for $30 \mathrm{~min}$ and then cooled in He to reach the adsorption temperature $(473 \mathrm{~K})$. Helium was saturated with pyridine (2.4-3.1 vol.\%) by passing through a flask with liquid pyridine (Fluka, $\geq 99.8 \%$ ) at room temperature. Pulsed chemisorption was performed until the surface was saturated and after purging with $\mathrm{He}$ for $3 \mathrm{~min}$, the temperature-programmed desorption run was started. The heating rate was equal to $33.6 \mathrm{~K} \mathrm{~min}^{-1}$ and the total flow rate was $20 \mathrm{ml}(\mathrm{STP}) \mathrm{min}^{-1}$.

\section{Results}

\subsection{Vanadia/titania catalysts prepared by solid-state reaction}

An effect of vanadia concentration on the steady-state specific rates of toluene oxidation was studied for vanadia/ titania catalysts prepared by solid-state reaction of $\mathrm{V}_{2} \mathrm{O}_{5}$ with $\mathrm{TiO}_{2}\left(0.76,1.6\right.$ and $3.7 \mathrm{ML} \mathrm{V/TiO}{ }_{2}$-ssr) (Fig. 1). It is seen that the steady-state specific activity of pure $\mathrm{V}_{2} \mathrm{O}_{5}$ and $\mathrm{TiO}_{2}$ is much lower as compared to the activity of vanadia/ titania catalysts. A deposition of vanadia on titania by solidstate reaction can result in considerable (more than 1 order of magnitude) increase of the specific activity (Fig. 1). A physical mixture of uncalcined $\mathrm{V}_{2} \mathrm{O}_{5} / \mathrm{TiO}_{2}$ showed activity 2-3 times lower than after calcination indicating that calcination is an important step in preparation of an active catalyst. It should be noticed also that a two-fold increase in the concentration of vanadia from 8 to $14.8 \%$ (1.6 and 3.7 $\mathrm{ML} \mathrm{V} / \mathrm{TiO}_{2}$-ssr samples) decreases the specific activity indicating that the concentration of active surface sites does not increase, but in contrast decreases.

The total selectivity to BA and BAc with vanadia/titania catalysts reaches $85-90 \%$, while over crystalline $\mathrm{V}_{2} \mathrm{O}_{5}$ it is slightly lower $(\sim 84 \%)$ even at lower conversion. Some deactivation due to coke formation was observed without a noticeable change of the total selectivity [20]. Titania is not only less active than vanadia/titania, but also less selective providing the selectivity to BA of only $51 \%$ and no BAc formation.

FT-Raman spectra (Fig. 2) demonstrate that in the uncalcined ball-milled $\mathrm{V}_{2} \mathrm{O}_{5} / \mathrm{TiO}_{2}$ mixture only $\mathrm{V}_{2} \mathrm{O}_{5}$ (994, $\left.696 \mathrm{~cm}^{-1}\right)$ and $\mathrm{TiO}_{2}\left(634 \mathrm{~cm}^{-1}\right)$, but no species of their interaction are present. The calcination results in a decrease of the $\mathrm{V}_{2} \mathrm{O}_{5}$ concentration and formation of monomeric $\left(1033 \mathrm{~cm}^{-1}\right)$ and polymeric $\left(920 \mathrm{~cm}^{-1}\right)$ vanadia species interacting with titania surface. In these species $\mathrm{V}^{5+}$ is tetracoordinated [1]. The obtained spectra are typical for pure V/Ti-oxides under dehydrated conditions $[21,22]$.

An increase of the concentration of vanadia in the calcined samples from 8 to $14.8 \%$ (1.6 and 3.7 ML V/ $\mathrm{TiO}_{2}$-ssr) is accompanied by an increase in the intensity of the $\mathrm{V}_{2} \mathrm{O}_{5}$ bands (Fig. 2). The same monomeric and polymeric species are formed. The presence of bulk $\mathrm{V}_{2} \mathrm{O}_{5}$ was also found in the $0.76{\mathrm{ML} \mathrm{V} / \mathrm{TiO}_{2}}_{2}$-ssr sample indicating not complete conversion of $\mathrm{V}_{2} \mathrm{O}_{5}$ to monolayer species in this sample. The difference between the intensity of the $\mathrm{V}_{2} \mathrm{O}_{5}$ band at $994 \mathrm{~cm}^{-1}$ before and after calcination was 


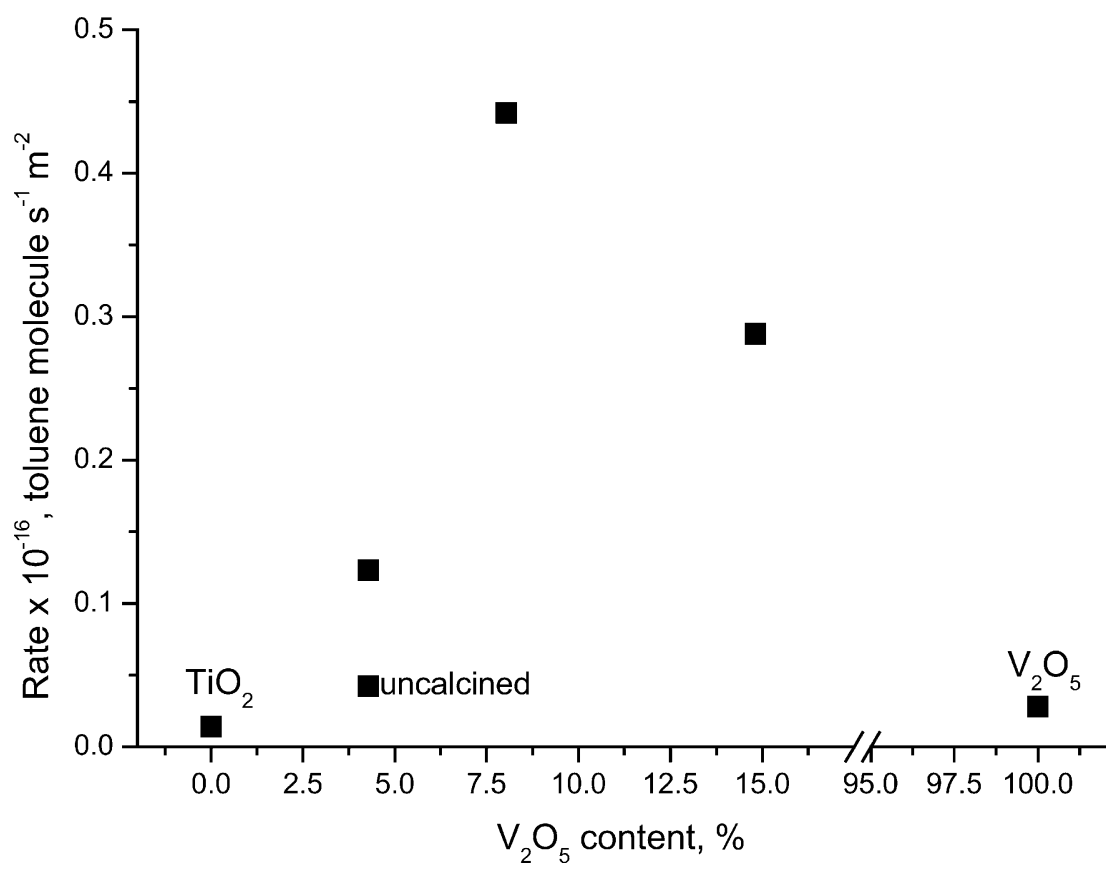

Fig. 1. Specific steady-state rates of toluene oxidation at $523 \mathrm{~K}$ as a function of vanadia content in vanadia/titania catalysts prepared by solid-state reaction.

used to estimate the amount of $\mathrm{V}_{2} \mathrm{O}_{5}$ interacted with the support. This value was found close to $0.9 \mathrm{ML}$ for the 1.6 and 3.7 ML V/TiO ${ }_{2}$-ssr samples, while it was 2.6 times lower for

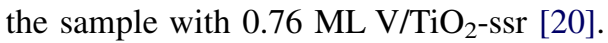

These data indicate that bulk $\mathrm{V}_{2} \mathrm{O}_{5}$ is not an active phase in toluene oxidation, since pure bulk $\mathrm{V}_{2} \mathrm{O}_{5}$ is almost not active. Therefore, an increase of the vanadium content in the samples over a certain value decreases the activity. Other methods of preparation of the catalysts were also used to understand the role of active species for catalysis.

\subsection{Vanadia/titania catalysts prepared by impregnation and grafting}

Specific rates of the toluene oxidation as a function of time-on-stream are shown in Fig. 3. Fig. 3a demonstrates the activity of bulk crystalline $\mathrm{V}_{2} \mathrm{O}_{5}, 2.6 \mathrm{ML} \mathrm{V} / \mathrm{TiO}_{2}$ catalyst prepared by impregnation and the same catalyst after $\mathrm{HNO}_{3}$ treatment. Fig. $3 \mathrm{~b}$ shows the activity of the $0.37 \mathrm{ML} \mathrm{V} / \mathrm{TiO}_{2}$ catalyst prepared by grafting and the activity of the same catalyst after $\mathrm{HNO}_{3}$ pre-treatment.

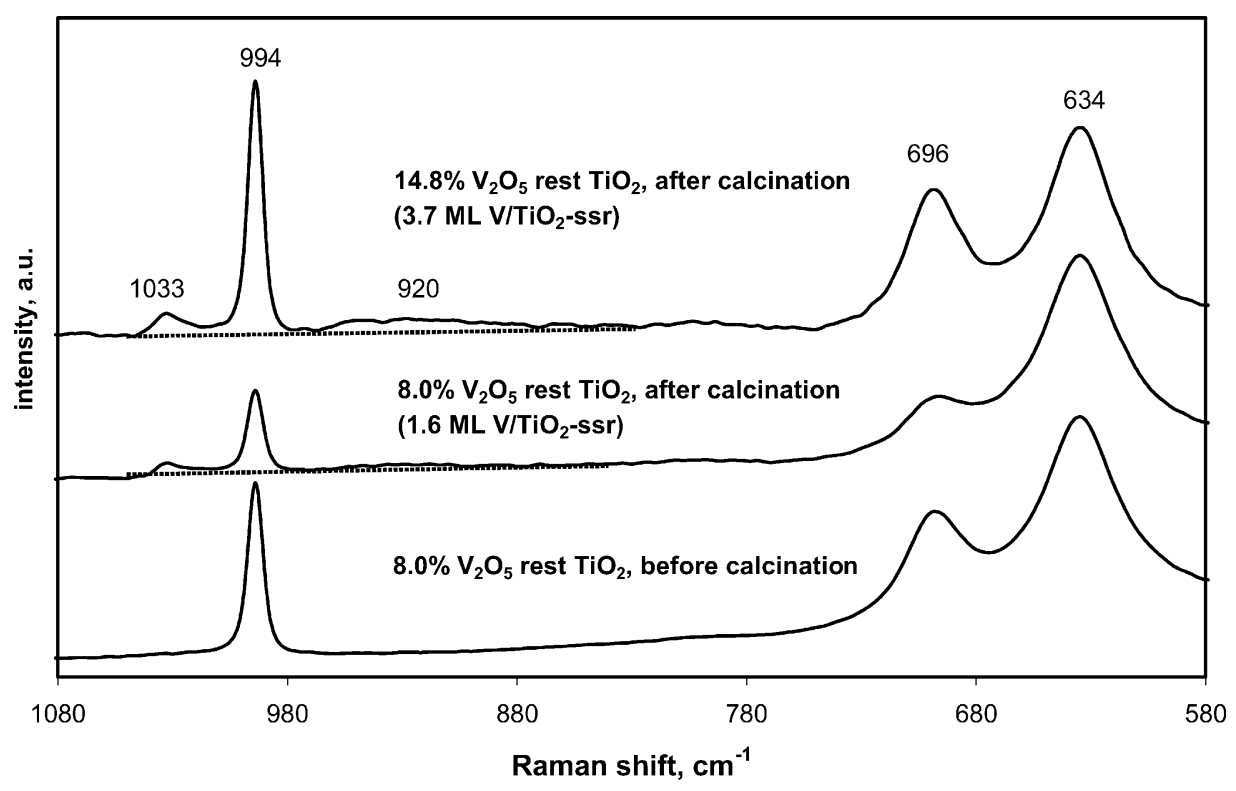

Fig. 2. FT-Raman spectra of the vanadia/titania catalysts prepared by solid-state reaction and ball-milled vanadia/titania physical mixture (before calcination). 

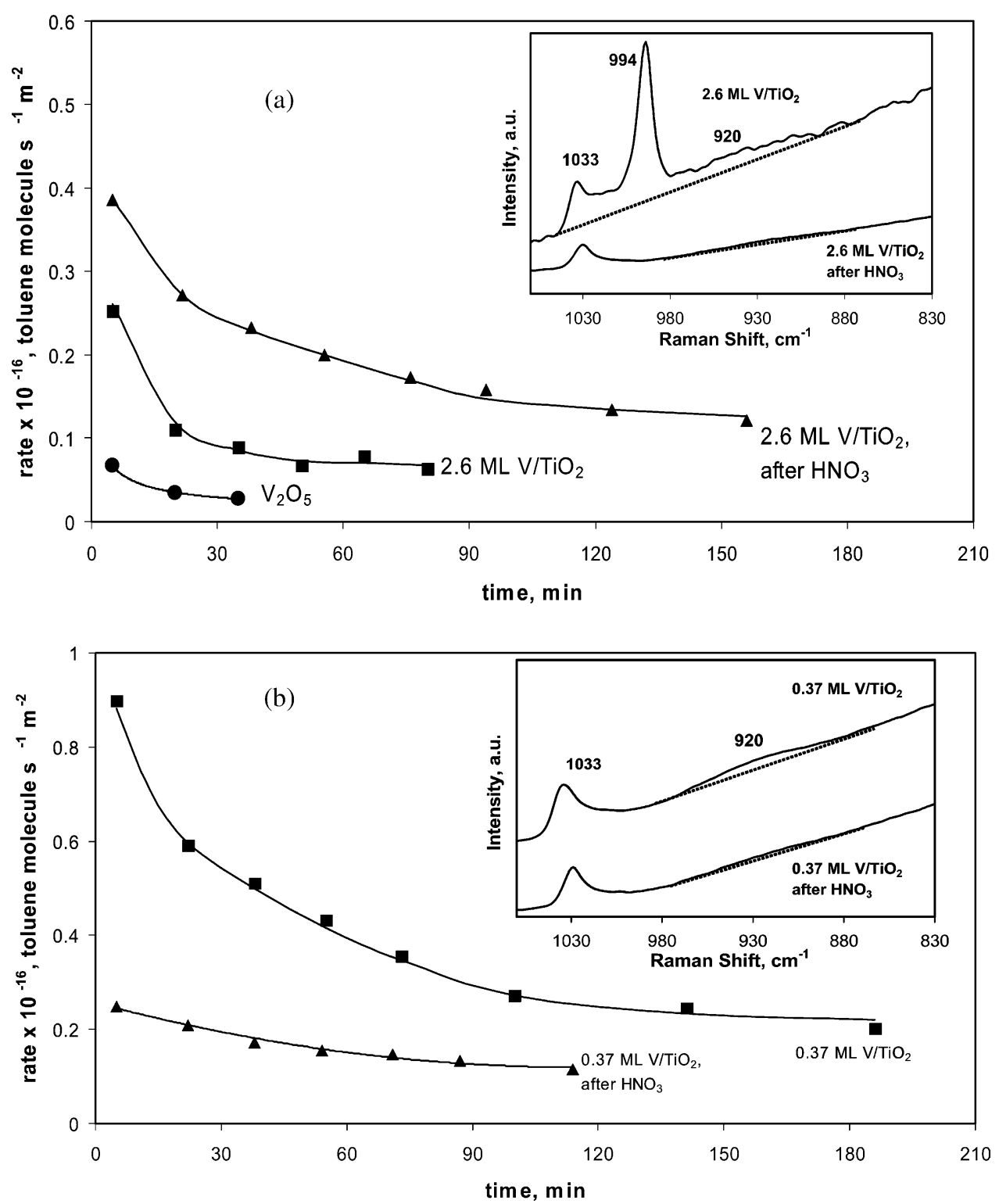

Fig. 3. FT-Raman spectra of the catalysts measured under dehydrated conditions (insets) and specific rates of toluene oxidation on time-on-stream at $523 \mathrm{~K}$ for: (a) $2.6 \mathrm{ML} \mathrm{V/TiO}$ and (b) $0.37 \mathrm{ML} \mathrm{V/TiO} 2$ catalysts before and after treatment in $\mathrm{HNO}_{3}$.

The 2.6 ML V/TiO 2 catalyst after $\mathrm{HNO}_{3}$ treatment possesses the activity four times higher than the bulk $\mathrm{V}_{2} \mathrm{O}_{5}$ and two times higher than the catalyst not treated in $\mathrm{HNO}_{3}$ (Fig. 3a). FT-Raman spectra demonstrate that the 2.6 ML V/TiO 2 catalyst contains $\mathrm{V}_{2} \mathrm{O}_{5}\left(994 \mathrm{~cm}^{-1}\right)$, monomeric $\left(1033 \mathrm{~cm}^{-1}\right)$ and polymeric $\left(920 \mathrm{~cm}^{-1}\right)$ vanadia species (Fig. 3a, inset) similarly to the catalysts prepared by solid-state reaction (Fig. 2). Washing in $\mathrm{HNO}_{3}$ completely removes bulk $\mathrm{V}_{2} \mathrm{O}_{5}$ and decreases strongly the concentration of the polymeric species. The intensity of the band associated with the monomeric species almost does not change.

These data also confirm that bulk $\mathrm{V}_{2} \mathrm{O}_{5}$ is not an active phase in the toluene oxidation over $\mathrm{V} / \mathrm{TiO}_{2}$ catalysts, because the specific activity of pure bulk $\mathrm{V}_{2} \mathrm{O}_{5}$ and the
2.6 $\mathrm{ML} \mathrm{V} / \mathrm{TiO}_{2}$ catalyst containing $\mathrm{V}_{2} \mathrm{O}_{5}$-crystallites is lower than the one of the catalyst containing only monolayer (monomeric and polymeric) species.

The activity of the $0.37 \mathrm{MLV} / \mathrm{TiO}_{2}$ catalyst was found to be higher than the activity of the same catalyst after the $\mathrm{HNO}_{3}$ treatment (Fig. 3b). FT-Raman spectra indicate that $\mathrm{HNO}_{3}$ removed almost completely the polymeric species, but not the monomeric ones (Fig. 3b, inset). The presence of small amount of polymeric species after this treatment is probably explained by equilibrium achieved between the monomeric and polymeric species during the thermal pretreatments. The activity of the $0.37 \mathrm{ML} \mathrm{V/TiO}{ }_{2}$ catalyst is higher than the one of all studied catalysts with only monolayer species (Fig. 3) and is comparable with the activity of the best catalysts prepared by solid-state reaction 


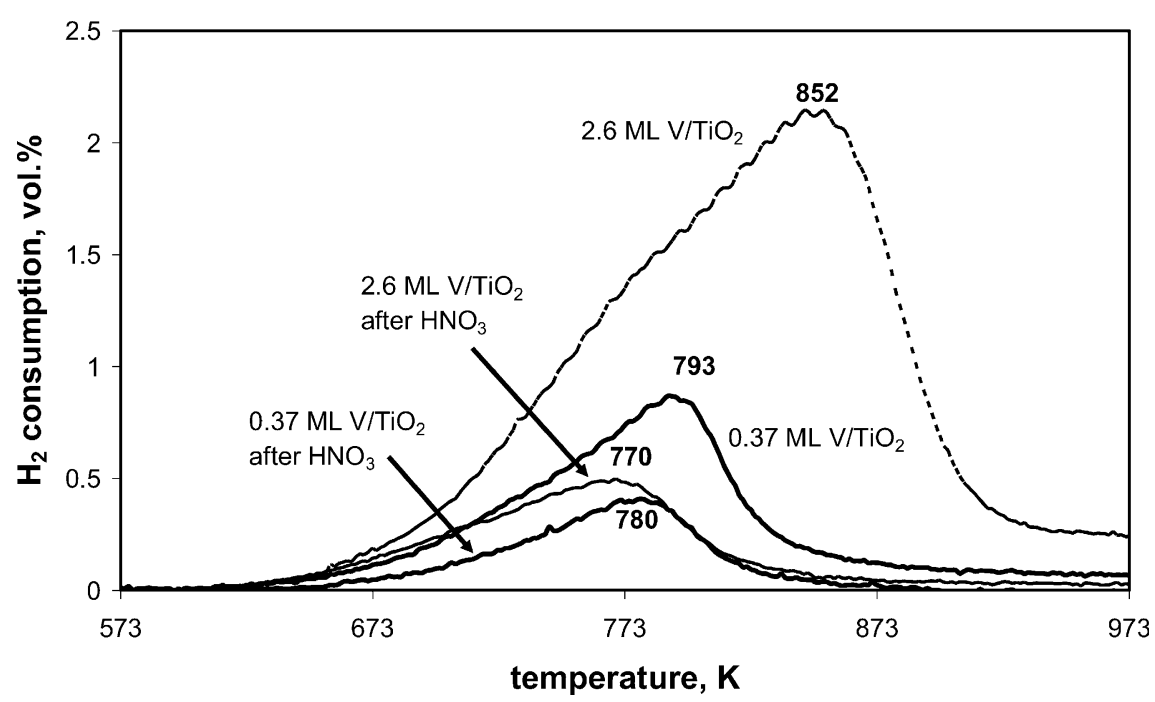

Fig. 4. TPR in hydrogen $\left(4 \mathrm{vol} . \% \mathrm{H}_{2}\right.$ in $\left.\mathrm{Ar}\right)$ of oxidised vanadia/titania catalysts $(0.37$ and $2.6 \mathrm{ML} \mathrm{V/TiO}$ taken with the same surface area) before and after treatment in $\mathrm{HNO}_{3}$.

(Fig. 1). These data suggest that the monomeric as well as polymeric species are active in the toluene oxidation.

To estimate the amount of vanadium removed by $\mathrm{HNO}_{3}$ from the samples, TPR experiments were performed. TPR indicates that the concentration of oxygen in the catalyst able to react with $\mathrm{H}_{2}$ decreases after the $\mathrm{HNO}_{3}$ treatment (Fig. 4). Integration of the concentration profiles was used for the coverage estimations basing on the known coverage of vanadia in the $0.37 \mathrm{ML} \mathrm{V/TiO}{ }_{2}$ catalyst $(0.37 \mathrm{ML})$. The estimation gives 0.22 and 0.16 for the $\mathrm{HNO}_{3}$ treated $2.6 \mathrm{ML}$ and $0.37 \mathrm{ML} \mathrm{V} / \mathrm{TiO}_{2}$ catalysts, respectively. This is in accordance with the measured catalytic activity (Fig. 3) showing that the higher is the concentration of monolayer species the higher is the rate of the reaction.

Thus, the specific activity order of the catalysts with the coverage less than a monolayer is the following $0.16<0.22$ $<0.37 \mathrm{ML}$. A further increase of the vanadia concentration in the catalysts up to $2.6 \mathrm{ML}\left(2.6 \mathrm{ML} \mathrm{V} / \mathrm{TiO}_{2}\right)$ results in a blockage of the active monolayer vanadia species by less active bulk $\mathrm{V}_{2} \mathrm{O}_{5}$. The same order of activity was observed at a higher temperature $(553 \mathrm{~K})$.

Another interesting feature is that the higher is the coverage of vanadia the higher is the degree of deactivation. This may be explained by an increased contribution of the polymeric species which probably contain the sites responsible for coke formation, contrary to the monomeric species.

The shown TPR profiles (Fig. 4) reflect the reducibility of vanadia species in hydrogen. Thus, with an increase of vanadia coverage, the maximum of the TPR peak shifts to higher temperatures in line with the literature data $[8,18,23,24]$. The insoluble monomeric species are the species easily reducible by hydrogen $\left(T_{\max } \leq 770-780 \mathrm{~K}\right)$ (Fig. 4). $T_{\max }$ for the reduction of the polymeric species is slightly higher $(\sim 800 \mathrm{~K})$ [18]. The maximal rate of reduction of amorphous bulk $\mathrm{V}_{2} \mathrm{O}_{5}$ is around $850 \mathrm{~K}$ (Fig. 4). Crystalline bulk $\mathrm{V}_{2} \mathrm{O}_{5}$ can be reduced effectively at $950-1000 \mathrm{~K}$
[6]. This reduction order of vanadia species in hydrogen agrees with the reducibility in toluene [25]. The trend of the oxidation ease of the reduced vanadia species by oxygen is the opposite. Bulk $\mathrm{V}_{2} \mathrm{O}_{5}$ after the reduction is the easiest to oxidise, while the reduced monomeric species is the most difficult for oxidation.

Hence, the monolayer species are active in toluene oxidation in aerobic conditions. To get the highest reaction rate a high surface concentration of monolayer species is needed. Bulk $\mathrm{V}_{2} \mathrm{O}_{5}$ is not necessary for activity and selectivity in the presence of oxygen. The question arises can the activity of vanadia be increased by doping? Potassium is known to improve the performance of some catalysts in different reactions [4]. This effect was supposed to be due to the change of the nature of surface vanadia species, catalyst acidity, and reducibility of the active phase.

\subsection{Vanadia/titania catalysts doped with $K$}

Effect of K-doping was studied with the catalyst containing about $0.2 \mathrm{ML}$ of vanadia since it was shown above that the monolayer species are responsible for activity. It is seen in Fig. 5 that the specific activity in toluene oxidation decreases while the concentration of $\mathrm{K}$ increases. The activity is almost negligible when the $\mathrm{K} / \mathrm{V}$ ratio is close to one, showing that active vanadia species are transformed into inactive ones.

The FT-Raman spectrum of the undoped $0.2{\mathrm{ML} \mathrm{V} / \mathrm{TiO}_{2}-}^{-}$ $\mathrm{K}_{0}$ catalyst (Fig. 5, inset) is similar to the one of the $0.37 \mathrm{ML}$ $\mathrm{V} / \mathrm{TiO}_{2}$ catalyst (Fig. 3b, inset) and demonstrates the presence of the monomeric as well as polymeric species. Doping by small amount of $\mathrm{K}$ results in the lengthening of the $\mathrm{V}=\mathrm{O}$ bond in the monomeric species $\left(1020 \mathrm{~cm}^{-1}\right.$, K-perturbed monomeric species) $[6,27]$. The bond length increases $0.007 \AA$ as was calculated using an equation proposed by Hardcastle and Wachs [27]. 


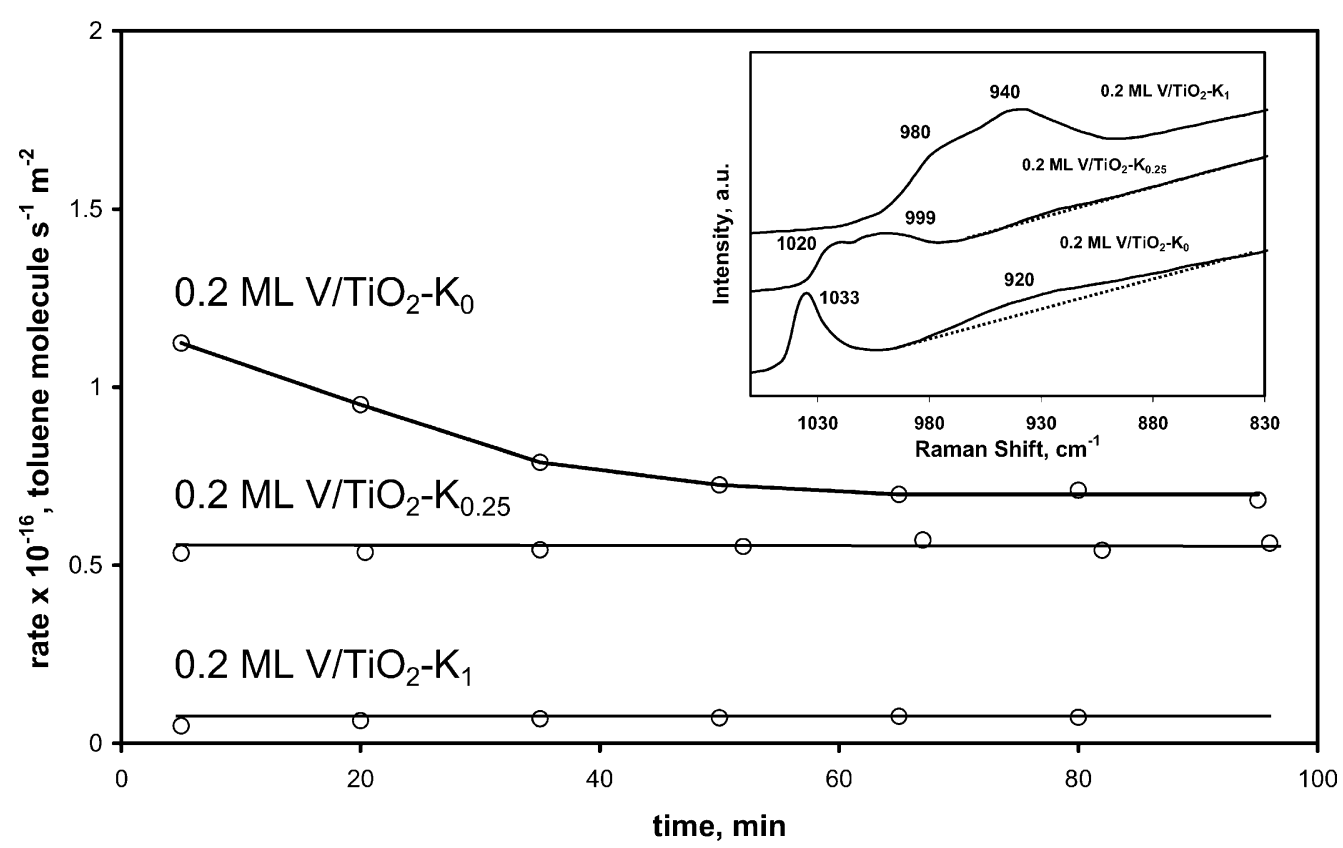

Fig. 5. Specific rates of toluene oxidation over vanadia/titania catalysts with different K/V ratio on time-on-stream at $573 \mathrm{~K}$. FT-Raman spectra of the catalysts measured under dehydrated conditions (inset).

The polymeric vanadia species are almost not present in the studied K-doped samples being transformed to K-doped monomeric species $\left(990 \pm 10 \mathrm{~cm}^{-1}\right)$. A part of the bridging $\mathrm{Ti}-\mathrm{O}-\mathrm{V}=\mathrm{O}$ fragments could be substituted by $\mathrm{K}-\mathrm{O}-\mathrm{V}=\mathrm{O}$ fragments as reported earlier [13]. This provides more strong lengthening of the $\mathrm{V}=\mathrm{O}$ bond $(0.017 \AA)$. Additionally, $\mathrm{KVO}_{3}$ is formed $\left(940 \mathrm{~cm}^{-1}\right)$.

Only $\mathrm{KVO}_{3}$ and $\mathrm{K}$-doped monomeric species are present in the catalyst with $\mathrm{K} / \mathrm{V}=1$. A correlation with the catalytic activity data indicates that these vanadia species are almost not active in toluene oxidation (Fig. 5), while the activity of the $\mathrm{K}$-perturbed monomeric species is very similar to the one of the undoped monomeric species. Important is that the increase in the $\mathrm{V}=\mathrm{O}$ bond length and weakening of this bond taking place by K-doping do not provide any increase in the toluene oxidation rate. In contrast, this rate decreases (Fig. 5).

Deactivation is not observed for the studied K-doped catalysts. This fact could be correlated with the one that the polymeric species probably containing the sites for coke formation are not present in the K-doped catalysts. To find the evidence of the Brønsted acidity of the polymeric species pyridine TPD experiments were performed (Fig. 6).

It is known that pyridine interacts with $\mathrm{TiO}_{2}$ surface forming only adsorbed species on Lewis acid sites and no

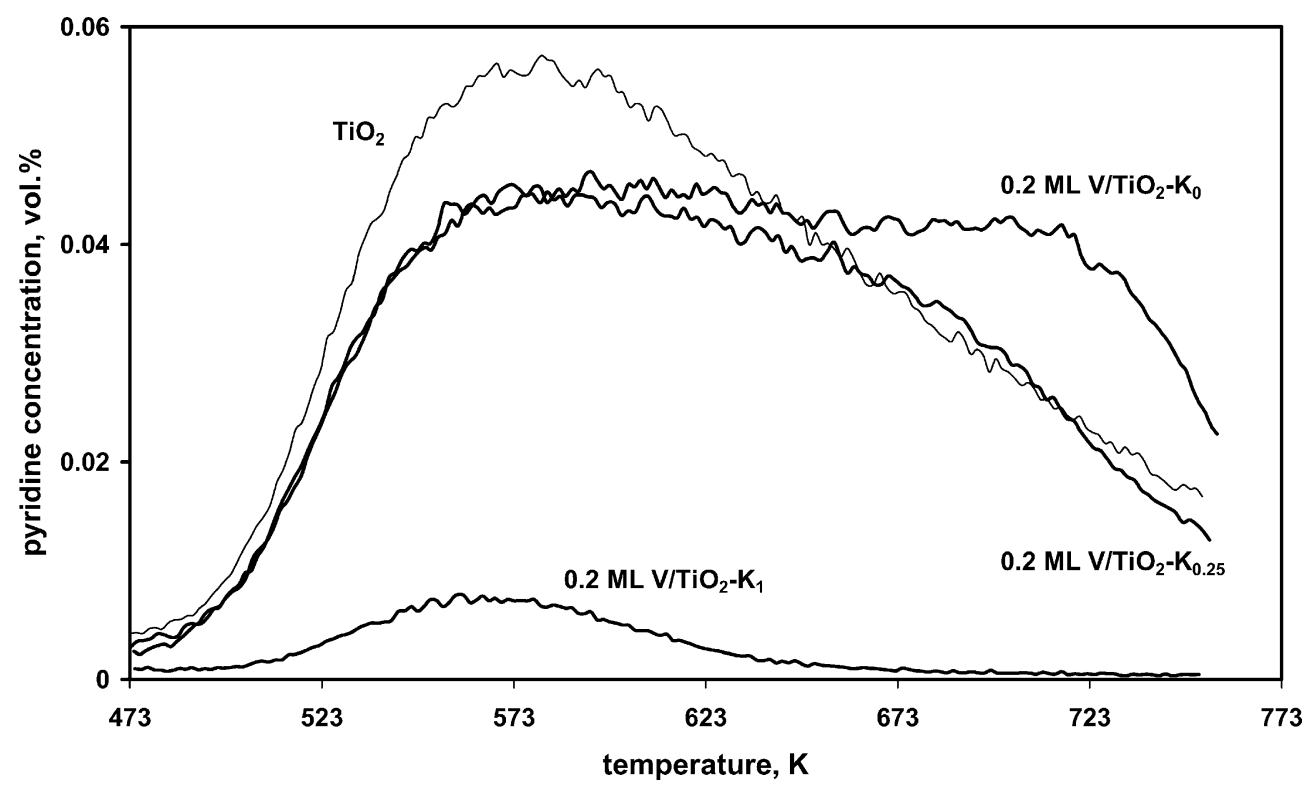

Fig. 6. Pyridine TPD from $\mathrm{TiO}_{2}$ and vanadia/titania catalysts with different $\mathrm{K} / \mathrm{V}$ ratio taken with the same surface area. 
species associated with Brønsted acid sites [28,29]. Hence, the observed pyridine TPD profile from $\mathrm{TiO}_{2}$ with a maximum at $573 \mathrm{~K}$ should be related to the $\mathrm{Ti}^{4+}$ Lewis acid sites.

Deposition of $0.2 \mathrm{ML}$ vanadia on titania results in a slight decrease of the intensity of this peak without any change in the shape and position of the peak maximum. In the presence of vanadia this peak should be related to titanium as well as to vanadium Lewis acid sites in accordance with FTIRS data $[28,29]$. However, the presence of more strongly adsorbed pyridine $(723 \mathrm{~K})$ is evident in the TPD profile of the undoped catalyst. This pyridine is removed from the surface in the form of $\mathrm{CO}$ and $\mathrm{CO}_{2}$ as was shown by mass-spectrometry. Pyridinium ion was found by FT-IRS to be stable to evacuation at $673 \mathrm{~K}$ [30]. Hence, the TPD peak at $723 \mathrm{~K}$ is associated with strong Brønsted acid sites, which are not present on the surface of $\mathrm{TiO}_{2}$ and K-doped catalysts, where almost no polymeric species was found (Fig. 5, inset). Only small amount of pyridine can adsorb on the catalyst with $\mathrm{K} / \mathrm{V}=1$ showing no acidity of such sample. This catalyst, as was mentioned, contains the K-doped monomeric species and $\mathrm{KVO}_{3}$, but does not contain the polymeric species and $\mathrm{V}_{2} \mathrm{O}_{5}$ with Brønsted acidity. Additionally, K-doping makes vanadia species more difficult to reduce than the undoped ones as was shown by TPR $[6,26]$.

The average total selectivity to BA and BAc was lower with the K-doped catalysts. It decreases from 82 to $65 \%$ after $\mathrm{K}$ doping $(\mathrm{K} / \mathrm{V}=0.25)$ in spite of the conversion with $\mathrm{K}$-doped catalyst was lower. K-doping decreases mainly the selectivity of BAc formation in favour of maleic anhydride and $\mathrm{CO}_{x}$ formation. Similar effect of potassium on vanadia species, catalytic activity, reducibility and acidity was observed at much higher vanadia loading (2 ML) $[6,26]$.

\section{Discussion}

The comparison of the specific activity in toluene oxidation of the samples with different vanadia content indicated that vanadia/titania catalysts could be one order of magnitude more active as compared to pure bulk $\mathrm{TiO}_{2}$ and $\mathrm{V}_{2} \mathrm{O}_{5}$ (Fig. 1). This suggests that considerably more active vanadia species are formed upon interaction of vanadia with titania. FT-Raman spectroscopy finds the polymeric and monomeric species in the active and selective catalysts independently on the method of preparation (Figs. 2 and 3, insets). The specific activity of the catalysts is controlled by the surface concentration of the monolayer vanadia species.

The presence of $\mathrm{V}_{2} \mathrm{O}_{5}$ is not necessary for catalysis in aerobic conditions. Moreover, at high vanadia coverage $\mathrm{V}_{2} \mathrm{O}_{5}$ blocks the active monolayer sites of toluene oxidation, decreasing the activity. This is in line with literature data for partial toluene [8] and $o$-xylene [31] oxidation as well as selective catalytic reduction of $\mathrm{NO}$ by $\mathrm{NH}_{3}$ [32].

It should be mentioned that in anaerobic conditions toluene can be oxidised by the oxygen of the catalyst [33]. However, the reactivity of the $2.6 \mathrm{ML} \mathrm{V} / \mathrm{TiO}_{2}$ and
$0.37 \mathrm{ML} \mathrm{V} / \mathrm{TiO}_{2}$ catalysts was found different. Gaseous BA and $\mathrm{CO}_{x}$ formation is observed only for the $2.6 \mathrm{ML} \mathrm{V} / \mathrm{TiO}_{2}$ catalyst, but not for the $0.37 \mathrm{ML} \mathrm{V/TiO}{ }_{2}$ one. In the latter case, DRIFTS studies found that adsorbed BA as well as $\mathrm{CO}_{x}$ formation intermediates are formed and retained on the surface, but either gas phase oxygen or oxygen of the bulk $\mathrm{V}_{2} \mathrm{O}_{5}$ are necessary for their desorption [33].

In the presence of oxygen both the monomeric and polymeric vanadia species oxidise toluene effectively to $\mathrm{BA}$ and BAc. The total BA and BAc selectivity is very similar independently on the concentration of vanadia. However, the polymeric species probably contain acid hydroxyl groups associated with the $\mathrm{V}-\mathrm{O}-\mathrm{V}$ bridges [1], which are responsible for coking and deactivation of the catalyst. Similar bridges exist in $\mathrm{V}_{2} \mathrm{O}_{5}$ also introducing Brønsted acidity [26]. This correlates with the increase of deactivation with vanadia coverage (Fig. 3) and with the effect of Kdoping decreasing deactivation (Figs. 5 and 6). The polymeric species are not present in the K-doped catalysts and in accordance the deactivation of these catalysts is not observed (Fig. 5).

Insoluble in $\mathrm{HNO}_{3}$ vanadia species was shown to consist mainly of the monomeric species, which do not possess Brønsted acidity [4]. Upon K-doping the $\mathrm{V}=\mathrm{O}$ bond in the monomeric species becomes slightly longer (K-perturbed monomeric species) probably because of electrostatic interaction of vanadyl oxygen with $\mathrm{K}$-cations on the surface. This seems not to affect the activity of the monomeric species in toluene oxidation. At high $\mathrm{K} / \mathrm{V}$ ratios the formation of the $\mathrm{K}$-doped monomeric and $\mathrm{KVO}_{3}$ species instead of polymeric species takes place, which are almost not active in toluene oxidation (Fig. 5). Moreover, their presence results in decreased selectivity to BAc, which is retained on the basic surface for a longer time being transformed to maleic anhydride and $\mathrm{CO}_{x}$ via consecutive surface reactions.

\section{Conclusions}

Monomeric and polymeric (monolayer) vanadia species are responsible for the catalytic activity in partial toluene oxidation over V/Ti-oxides independently on the methods of their preparation. Bulk $\mathrm{V}_{2} \mathrm{O}_{5}$ and $\mathrm{TiO}_{2}$ possess considerably lower activity and their presence in big excess should be avoided.

Polymeric species and $\mathrm{V}_{2} \mathrm{O}_{5}$ are responsible for coke formation and deactivation of vanadia/titania catalysts in toluene oxidation. This effect is probably due to acid hydroxyl groups associated with bridging oxygen.

Bulk $\mathrm{V}_{2} \mathrm{O}_{5}$ and polymeric vanadia could be selectively removed by diluted $\mathrm{HNO}_{3}$ from the catalyst, while monomeric vanadia species are retained on the titania surface.

Catalyst deactivation can be suppressed by doping with potassium, which interacts with Brønsted acidic sites on the catalyst surface. At the same time activity decreases due to diminished amount of monolayer species, which are par- 
tially transformed into inactive K-doped monomeric and $\mathrm{KVO}_{3}$ species.

\section{References}

[1] I.E. Wachs, B.M. Weckhuysen, Appl. Catal. A 157 (1997) 67.

[2] G.C. Bond, J.C. Vedrine, Catal. Today 20 (1994) 171.

[3] G.T. Went, L.-J. Leu, A.T. Bell, J. Catal. 134 (1992) 479.

[4] B. Grzybowska-Swierkosz, Appl. Catal. A 157 (1997) 263.

[5] G.C. Bond, Appl. Catal. A 157 (1997) 91.

[6] D.A. Bulushev, F. Rainone, L. Kiwi-Minsker, A. Renken, Langmuir 17 (2001) 5276.

[7] D.A. Bulushev, L. Kiwi-Minsker, V.I. Zaikovskii, A. Renken, J. Catal. 193 (2000) 145.

[8] H.K. Matralis, C. Papadopoulou, C. Kordulis, A.A. Elguezabal, V.C. Corberan, Appl. Catal. A: Gen. 126 (1995) 365.

[9] J. Huuhtanen, M. Sanati, A. Andersson, S.L.T. Andersson, Appl. Catal. 97 (1993) 197.

[10] A.J. vanHengstum, J.G. Ommen, H. Bosch, P.J. Gellings, Appl. Catal. 8 (1983) 369.

[11] B. Jonson, B. Rebenstorf, R. Larsson, S.L.T. Andersson, J. Chem. Soc., Faraday Trans. 84 (1988) 3547.

[12] G. Deo, I.E. Wachs, J. Catal. 146 (1994) 335.

[13] G. Ramis, G. Busca, F. Bregani, Catal. Lett. 18 (1993) 299.

[14] G. Centi, E. Giamello, D. Pinelli, F. Trifiro, J. Catal. 130 (1991) 220

[15] J.P. Nogier, Catal. Today 20 (1994) 23.

[16] V.M. Bondareva, T.V. Andrushkevich, O.B. Lapina, Catal. Today 61 (2000) 173.
[17] S. Besselmann, E. Loffler, M. Muhler, J. Mol. Catal. A 162 (2000) 401.

[18] D.A. Bulushev, L. Kiwi-Minsker, F. Rainone, A. Renken, J. Catal. 205 (2002) 115.

[19] J. Haber, T. Machej, E.M. Serwicka, I.E. Wachs, Catal. Lett. 32 (1995) 101.

[20] D.A. Bulushev, L. Kiwi-Minsker, A. Renken, Catal. Today 57 (2000) 231.

[21] J.-M. Jehng, G. Deo, B.M. Weckhuysen, I.E. Wachs, J. Mol. Catal. A 110 (1996) 41.

[22] B. Olthof, A. Khodakov, A.T. Bell, E. Iglesia, J. Phys. Chem. B 104 (2000) 1516.

[23] A. Baiker, P. Dollenmeier, M. Glinski, A. Reller, Appl. Catal. 35 (1987) 351.

[24] G. Bond, S.F. Tahir, Appl. Catal. 71 (1991) 1.

[25] S. Besselmann, C. Freitag, O. Hinrichsen, M. Muhler, Phys. Chem. Chem. Phys. 3 (2001) 4633.

[26] L. Kiwi-Minsker, D.A. Bulushev, F. Rainone, A. Renken, J. Mol. Catal. A 184 (2002) 223.

[27] F.D. Hardcastle, I.E. Wachs, J. Phys. Chem. 95 (1991) 5031.

[28] F. Hatayama, T. Ohno, T. Maruoka, T. Ono, H. Miyata, J. Chem. Soc., Faraday Trans. 87 (1991) 2629.

[29] G. Busca, Langmuir 2 (1986) 577.

[30] T.J. Dines, C.H. Rochester, A.M. Ward, J. Chem. Soc., Faraday Trans. 87 (1991) 1611.

[31] M.G. Nobbenhuis, A. Baiker, P. Barnickel, A. Wokaun, Appl. Catal. 85 (1992) 157.

[32] M.D. Amiridis, I.E. Wachs, G. Deo, J.-M. Jehng, D.S. Kim, J. Catal. 161 (1996) 247.

[33] F. Rainone, D.A. Bulushev, L. Kiwi-Minsker, A. Renken, Phys. Chem. Chem. Phys. 5 (2003) 4445. 